\title{
Are hospitals delivering appropriate VTE prevention? The venous thromboembolism study to assess the rate of thromboprophylaxis (VTE start)
}

\author{
A. Amin - A. C. Spyropoulos - P. Dobesh - A. Shorr · \\ M. Hussein · E. Mozaffari · J. S. Benner
}

Published online: 23 June 2009

(c) The Author(s) 2009. This article is published with open access at Springerlink.com

\begin{abstract}
The 7th conference of the American College of Chest Physicians (ACCP7) provides recommendations on the type, dose, and duration of thromboprophylaxis in hospitalized patients at risk of venous thromboembolism (VTE), but the extent to which hospitals follow these criteria has not been well studied. Discharge and billing records for patients admitted to any of 16 acute-care hospitals from January 2005 to December 2006 were obtained. Patients 18 years or older who had an inpatient stay $\geq 2$ days and no apparent contraindications for thromboprophylaxis were grouped into the categories of critical care, surgery and medically ill before being assessed for additional VTE risk factors based on the diagnostic criteria outlined in ACCP7. For patients at risk, the recommended
\end{abstract}

A. Amin ( $₫)$

Department of Medicine, University of California Irvine, Irvine, CA, USA

e-mail: anamin@uci.edu

A. C. Spyropoulos

ABQ Health Partners and University of New Mexico Health

Sciences Center and College of Pharmacy, Albuquerque

NM, USA

P. Dobesh

College of Pharmacy, University of Nebraska Medical Center,

Omaha, NE, USA

A. Shorr

Washington Hospital Center, Washington, DC, USA

M. Hussein - J. S. Benner

Health Economics and Outcomes Research, IMS Health, Inc.,

Falls Church, VA, USA

E. Mozaffari

Sanofi-aventis, Brigewater, NJ, USA type (mechanical or pharmacologic), dose, and duration of thromboprophylaxis was identified based on the guidelines and compared to the regimen actually received, if any. Among the 258,556 hospitalized patients, 68,278 (26.4\%) were determined to be at risk of VTE without apparent contraindications for thromboprophylaxis. The proportions of patients who received the appropriate type, dose, and duration of thromboprophylaxis were 10.5, 9.8, and $17.9 \%$ for critical care, medical, and surgical patients, respectively. Of those at risk, $36.8 \%$ received no thromboprophylaxis and an additional $50.2 \%$ received thromboprophylaxis deemed inappropriate for one or more reasons. The implementation of ACCP7 guidelines for type, dosage, and duration of thromboprophylaxis is low in patients at risk of VTE. There is a need for physicians and health systems to improve awareness and implementation of recommended thromboprophylaxis.

Keywords Venous thromboembolism - Guidelines · Health care quality

$\begin{array}{ll}\begin{array}{l}\text { Abbreviations } \\ \text { ACCP }\end{array} & \begin{array}{l}\text { American college of chest physicians } \\ \text { American college of chest physicians 7th } \\ \text { and most recent guidelines }\end{array} \\ \text { ENDORSE } & \begin{array}{l}\text { Epidemiologic international day for the } \\ \text { evaluation of patients at risk for venous } \\ \text { thromboembolism in the acute hospital } \\ \text { care setting }\end{array} \\ \text { ICD-9-CM } & \begin{array}{l}\text { International classifications of diseases, } \\ \text { 9th revision, clinical modification } \\ \text { IMPROVE }\end{array} \\ \text { International medical prevention registry } \\ \text { on venous thromboembolism } \\ \text { Length of stay }\end{array}$


VTE Venous thromboembolism

VTE START Venous thromboembolism study to assess the rate of thromboprophylaxis

\section{Introduction}

The American College of Chest Physicians (ACCP) has issued guidelines for the prevention of venous thromboembolism (VTE) since 1986. The 7th and most recent update of these guidelines (ACCP7), published in 2004, are based on a comprehensive assessment of the literature on risk factors and effective thromboprophylaxis regimens [1]. These guidelines identify specific groups of medical and surgical patients at risk of VTE and provide recommendations for the type (mechanical, pharmacologic, or combination), dose and duration of thrombo- prophylactic measures. The Joint Commission on Accreditation of Healthcare Organizations and the National Quality Forum have recognized the importance of using thromboprophylaxis to prevent VTE in hospitalized patients [2]. Moreover, in 2007 two new quality indicators were added to Medicare's Surgical Care Improvement Project: Thromboprophylaxis ordered for surgery patient, and thromboprophylaxis within $24 \mathrm{~h}$ pre/post surgery[3].

Despite the long-standing availability of evidence-based guidelines for thromboprophylaxis, compliance with these in hospitalized patients at risk has remained low. Previous retrospective studies using patient chart reviews have shown that 25 to $84 \%$ of hospitalized patients are at risk of VTE and that only 23 to $46 \%$ of these patients receive any form of thromboprophylaxis [4-10]. However, assessments of evidence-based thromboprophylaxis are more clinically meaningful when all of the criteria for appropriate thromboprophylaxis are measured. To date, no studies have assessed the appropriateness of thromboprophylaxis against ACCP7 recommendations for the type, dose, and duration of therapy. Assessments using electronic discharge-summary and billing records offer the advantage of including large samples of patients at risk for VTE and the ability to assess not only the rate of thromboprophylaxis but also its appropriateness with respect to type, dose and duration. The primary aim of this project was to support quality improvement efforts at selected US hospitals by measuring implementation of ACCP7 guidelines for type, dose, and duration of thromboprophylaxis across a broad range of medical and surgical conditions.

\section{Methods}

\section{Data source}

The Venous Thromboembolism Study to Assess the Rate of Thromboprophylaxis (VTE START) was part of a quality improvement initiative designed to help hospitals assess and improve their use of appropriate thromboprophylaxis. A Steering Committee of researchers and clinical experts in thromboprophylaxis were responsible for the design and implementation of the project. Participation was offered by the Steering Committee to a convenience sample of acute-care hospitals of various sizes in urban and rural areas of the Midwest and Southwest. Of 16 that participated, 13 hospitals were affiliated with a single health system, and two hospitals had implemented some type of a prophylaxis program during the 2005-2006 period. Participating hospitals provided electronic patientlevel discharge-summary and billing records for 20052006. Discharge-summary records contained demographic data (age, gender, race), admission and discharge dates, referral source and type of insurance. Primary and secondary codes for diagnoses and procedures (in International Classifications of Diseases, 9th revision, Clinical Modification [ICD-9-CM] format) and specialty of the attending or admitting physician were also available. Billing records provided daily information on inpatient services provided and pharmacy data describing medication type, quantity, and dose. Hospital-level data included bed count and indicators for teaching or non-teaching, rural or urban, and for-profit or non-profit.

All patient records were de-identified by the hospitals in compliance with the Privacy Rule of the Health Insurance Portability and Accountability Act of 1996 [13]. The study protocol was approved or exempted by the Institutional Review Board governing each participating institution. After the study, participating hospitals were provided the pooled results for all 16 hospitals as well as the results specific to their institution for purposes of comparison and use in their quality improvement initiatives.

\section{Study population}

Patients 18 years and older at admission, who had an inpatient stay $\geq 2$ days between January 1, 2005 and December 31, 2006, were eligible for inclusion. Patients meeting one or more of the following were excluded from the analyses: (1) transferred from another acute-care facility where they may have already received thromboprophylaxis; (2) pregnancy-related discharge diagnosis owing to precautions for anticoagulant use in pregnant women; (3) other conditions where thromboprophylaxis could be contraindicated were also excluded based on ICD-9-CM diagnosis and procedure codes for active bleeding or indicating a potentially high risk of bleeding due to certain liver diseases, malignant hypertension, certain blood diseases, active peptic ulcer and renal dysfunction; and (4) discharge diagnosis of VTE in order to distinguish between VTE prophylaxis and treatment. 


\section{Patients at risk}

Patients were grouped into potentially at-risk cohorts based on ACCP7 guidelines. We created mutually exclusive groups of critical care, surgical, and medical patients based on hospital discharge-summary and billing records. For example a patient was flagged as critical care if he/she had a billing code indicative of time he/she spent in critical care unit. Surgical and medical patients were identified using ICD9-CM diagnosis and procedure codes indicative of the surgery and condition of interest (see Table 1, technical appendix). Patients were placed in the most severe group for which they qualified (critical care being the highest in severity and medical conditions being the lowest) For instance a trauma patient who required surgery was classified as surgery. Next, they were subclassified into seven mutually exclusive diagnostic groups adapted from ACCP7 (see Table 1) [1]. Surgical procedures were classified as non-major (operations other than abdominal lasting $<45 \mathrm{~min}$ ) or major (any intra-abdominal operation and any other operations lasting $\geq 45 \mathrm{~min}$ ) [14]. Low, moderate and high levels of surgical risk were defined based on ACCP7 risk factors [1]. The final determination of at-risk status and recommended thromboprophylaxis was based on assessments of "additional risk factors" as specified in ACCP7 [1]. Risk factors were identified using relevant ICD9-CM diagnoses and procedure codes. Risk factors such as smoking and immobility that are difficult to determine using ICD9-CM codes were not captured.

\section{Study measures}

The primary endpoint was the rate of appropriate thromboprophylaxis. This assessment was based upon ACCP7 recommendations for each cohort of patients at risk. Appropriate thromboprophylaxis rates were determined using four criteria: (1) whether the patient received any thromboprophylaxis; (2) whether the appropriate type of thromboprophylaxis (mechanical or pharmacologic) was used; (3) whether the pharmacologic regimen (if any) was given at a dose greater or equal to the minimum recommended daily dose; and (4) whether the regimen was administered for greater or equal to the recommended number of days. ACCP7 recommends thromboprophylaxis for the length of stay (LOS) for patients at risk of VTE. However, for medical patients, duration was considered sufficient in this study if thromboprophylaxis was received for LOS minus 1 day to accommodate partial days of stay. For surgical patients, duration of LOS minus 2 days was considered sufficient to accommodate partial days of stay and procedures for which thromboprophylaxis is not recommended on the day of surgery. Duration of prophylaxis for pharmacologic agents was calculated by summing up the number days for which a relevant billing code was recorded. For mechanical prophylaxis, duration was calculated as the total number of days between the first billing date during which a relevant billing code was recorded and the discharge date. The rate of appropriate thromboprophylaxis was calculated as the total number of appropriately treated patients divided by the number of patients at risk of VTE. Appropriate thromboprophylaxis rates were determined for the full study period and for each calendar quarter, as well as by primary attending physician specialty, hospital characteristics and LOS.

The study's secondary endpoint was the proportion of all hospitalized patients at risk of VTE. This was calculated as the total number of patients at risk divided by the total number of discharged patients.

\section{Results}

Patient population and characteristics

Of 258,556 patients for whom data were available, 135,954 $(53 \%)$ met at least one exclusion criterion (Fig. 1). After establishing the main diagnostic groups (critical care, surgical, and medical) and applying the additional risk-factor criteria specified in ACCP7, we identified 68,278 patients at risk of VTE (26.4\%). Of these, approximately equal percentages were critical care, surgical, and medical patients. Most patients were female, elderly, and Caucasian with an average LOS of 5.3 days, attended by internists and primary care physicians, and insured by public (mostly Medicare and Medicaid) or commercial health insurance (Table 1).

Rate of appropriate thromboprophylaxis

A total of 43,125 patients, or $63.2 \%$ of those at risk of VTE, received some type of mechanical or pharmacologic thromboprophylaxis (Table 2). This rate was greatest for critical care patients, followed by surgical then medical. However, only $12.9 \%$ of at-risk patients received appropriate type and dose and duration based on ACCP7 criteria (20.4\% of those receiving any thromboprophylaxis). The rate of appropriate thromboprophylaxis was highest for surgical patients, followed by critical care and medical patients (17.9, 10.5, and 9.8\%, respectively). Among documented physician specialties, the rate of appropriate thromboprophylaxis was highest for orthopedics followed by cardiology ( 32.0 and $18.3 \%$, respectively), but still poor overall. Across all categories, $87.1 \%$ of at-risk patients received either no thromboprophylaxis or inappropriate thromboprophylaxis.

The leading reason for failure to meet ACCP7 criteria (Table 2) was no thromboprophylaxis at all $(36.8 \%$ of 
Table 1 Characteristics of patients at risk of VTE in 2005-2006, by major diagnostic group $(n=68,278)$

\begin{tabular}{|c|c|c|c|c|c|c|c|c|c|c|}
\hline \multirow{2}{*}{$\begin{array}{l}\text { Patient } \\
\text { characteristics }\end{array}$} & \multirow{2}{*}{$\begin{array}{l}\text { Critical } \\
\text { care }\end{array}$} & \multicolumn{4}{|l|}{ Surgery } & \multicolumn{4}{|l|}{ Medical } & \multirow[t]{2}{*}{ Total } \\
\hline & & $\begin{array}{l}\text { General, } \\
\text { vascular, } \\
\text { gynecologic, } \\
\text { laparoscopic, } \\
\text { and urologic }\end{array}$ & Orthopedic & Neurosurgery & $\begin{array}{l}\text { Total } \\
\text { surgery }\end{array}$ & $\begin{array}{l}\text { Trauma, } \\
\text { spinal } \\
\text { cord, } \\
\text { injuries, } \\
\text { and, burns }\end{array}$ & $\begin{array}{l}\text { General } \\
\text { medical }\end{array}$ & Cancer & $\begin{array}{l}\text { Total } \\
\text { medical }\end{array}$ & \\
\hline $\begin{array}{l}\text { Number of } \\
\text { patients at } \\
\text { risk of VTE }\end{array}$ & 21,081 & 15,783 & 7,776 & 1,183 & 24,742 & 1,720 & 19,011 & 1,724 & 22,455 & 68,278 \\
\hline \multicolumn{11}{|l|}{ Age, $\%$} \\
\hline $18-39$ & 10.2 & 18.7 & 3.3 & 11.2 & 13.5 & 18.5 & 0.0 & 1.0 & 1.5 & 8.5 \\
\hline $40-49$ & 12.1 & 21.6 & 8.4 & 10.1 & 16.9 & 13.5 & 11.8 & 6.9 & 11.6 & 13.7 \\
\hline $50-59$ & 18.6 & 20.2 & 20.6 & 14.9 & 20.1 & 16.8 & 15.5 & 15.0 & 15.5 & 18.1 \\
\hline $60-69$ & 20.7 & 16.2 & 26.2 & 23.1 & 19.7 & 13.2 & 18.6 & 24.0 & 18.6 & 19.7 \\
\hline $70+$ & 38.3 & 23.3 & 41.6 & 40.8 & 29.9 & 38.0 & 54.1 & 53.0 & 25.8 & 40.0 \\
\hline \multicolumn{11}{|l|}{ Race, \% } \\
\hline Caucasian & 81.8 & 77.0 & 88.5 & 80.6 & 80.8 & 85.1 & 84.2 & 87.9 & 84.6 & 82.3 \\
\hline $\begin{array}{r}\text { African } \\
\text { American }\end{array}$ & 7.7 & 10.2 & 3.6 & 4.6 & 7.9 & 3.8 & 7.3 & 6.1 & 6.9 & 7.5 \\
\hline Asian & 0.9 & 1.1 & 0.4 & 0.7 & 0.8 & 0.8 & 0.8 & 0.6 & 0.8 & 0.8 \\
\hline Hispanic & 6.8 & 9.2 & 4.6 & 11.7 & 7.9 & 8.7 & 5.3 & 3.8 & 5.5 & 6.8 \\
\hline Other & 0.8 & 0.9 & 0.7 & 0.9 & 0.8 & 0.2 & 0.5 & 0.3 & 0.4 & 0.7 \\
\hline $\begin{array}{l}\text { Not } \\
\quad \text { documented }\end{array}$ & 2.0 & 1.6 & 2.2 & 1.5 & 1.8 & 1.4 & 1.9 & 1.2 & 1.8 & 1.9 \\
\hline \multicolumn{11}{|l|}{ Gender, $\%$} \\
\hline Male & 51.1 & 35.8 & 36.8 & 50.9 & 36.8 & 41.0 & 40.1 & 45.1 & 40.6 & 42.5 \\
\hline Female & 48.9 & 64.2 & 63.2 & 49.1 & 63.2 & 59.0 & 59.9 & 54.9 & 59.4 & 57.5 \\
\hline $\begin{array}{l}\text { Not } \\
\quad \text { documented }\end{array}$ & 0.0 & 0.0 & 0.0 & 0.0 & 0.0 & 0.0 & 0.0 & 0.0 & 0.0 & 0.0 \\
\hline $\begin{array}{l}\text { Length of } \\
\text { staty, days(SD) }\end{array}$ & $6.3(6.4)$ & $5.3(5.2)$ & $4.3(2.5)$ & $4.6(5.2)$ & $5.0(4.5)$ & $5.6(4.8)$ & $4.5(2.9)$ & $6.1(4.4)$ & $4.7(3.3)$ & $5.3(4.9)$ \\
\hline \multicolumn{11}{|l|}{ Referral source, $\%$} \\
\hline Physician & 61.6 & 56.2 & 58.3 & 65.3 & 57.3 & 69.7 & 56.9 & 56.7 & 57.9 & 58.8 \\
\hline ER & 35.2 & 42.9 & 41.2 & 33.6 & 41.9 & 28.4 & 42.0 & 42.1 & 41.0 & 39.5 \\
\hline Other & 3.1 & 0.9 & 0.6 & 1.0 & 0.8 & 1.9 & 1.0 & 1.2 & 1.1 & 1.6 \\
\hline $\begin{array}{l}\text { Not } \\
\quad \text { documented }\end{array}$ & 0.0 & 0.0 & 0.0 & 0.1 & 0.0 & 0.0 & 0.0 & 0.0 & 0.0 & 0.0 \\
\hline \multicolumn{11}{|c|}{ Primary attending physician specialty ${ }^{\ddagger}, \%$} \\
\hline Cardiology & 22.9 & 1.7 & 0.1 & 0.3 & 1.1 & 0.2 & 6.8 & 4.6 & 6.1 & 9.5 \\
\hline $\begin{array}{l}\text { Internal } \\
\text { medicine and } \\
\text { primary care }\end{array}$ & 43.6 & 24.0 & 7.4 & 4.3 & 17.9 & 26.7 & 76.5 & 55.7 & 71.1 & 43.3 \\
\hline Neurology & 8.6 & 0.9 & 6.1 & 54.1 & 5.0 & 1.6 & 0.7 & 0.2 & 0.8 & 4.7 \\
\hline Oncology & 0.7 & 3.0 & 0.1 & 0.5 & 1.9 & 0.1 & 0.1 & 18.3 & 1.5 & 1.4 \\
\hline Orthopedic & 1.9 & 1.6 & 72.8 & 14.0 & 24.5 & 34.4 & 0.6 & 1.3 & 3.3 & 10.6 \\
\hline Surgery & 9.4 & 37.6 & 0.8 & 3.6 & 24.4 & 28.0 & 1.1 & 3.1 & 3.3 & 12.8 \\
\hline Other & 9.4 & 28.2 & 10.2 & 22.4 & 22.3 & 4.1 & 7.1 & 10.3 & 7.1 & 13.3 \\
\hline $\begin{array}{l}\text { Not } \\
\quad \text { documented }\end{array}$ & 3.7 & 3.1 & 2.5 & 0.8 & 2.8 & 4.8 & 7.0 & 6.6 & 6.8 & 4.4 \\
\hline
\end{tabular}


Table 1 continued

\begin{tabular}{|c|c|c|c|c|c|c|c|c|c|c|}
\hline \multirow{2}{*}{$\begin{array}{l}\text { Patient } \\
\text { characteristics }\end{array}$} & \multirow{2}{*}{$\begin{array}{l}\text { Critical } \\
\text { care }\end{array}$} & \multicolumn{4}{|l|}{ Surgery } & \multicolumn{4}{|l|}{ Medical } & \multirow[t]{2}{*}{ Total } \\
\hline & & $\begin{array}{l}\text { General, } \\
\text { vascular, } \\
\text { gynecologic, } \\
\text { laparoscopic, } \\
\text { and urologic }\end{array}$ & Orthopedic & Neurosurgery & $\begin{array}{l}\text { Total } \\
\text { surgery }\end{array}$ & $\begin{array}{l}\text { Trauma, } \\
\text { spinal } \\
\text { cord, } \\
\text { injuries, } \\
\text { and, burns }\end{array}$ & $\begin{array}{l}\text { General } \\
\text { medical }\end{array}$ & Cancer & $\begin{array}{l}\text { Total } \\
\text { medical }\end{array}$ & \\
\hline \multicolumn{11}{|l|}{ Payer type, $\%$} \\
\hline Public $§$ & 48.4 & 32.5 & 48.1 & 47.3 & 38.1 & 44.0 & 63.8 & 62.8 & 62.2 & 49.2 \\
\hline Commercial & 43.7 & 59.3 & 49.1 & 46.3 & 55.5 & 39.6 & 30.9 & 34.6 & 31.9 & 44.1 \\
\hline $\begin{array}{l}\text { No } \\
\text { insurance }\end{array}$ & 7.2 & 7.0 & 0.8 & 1.7 & 4.8 & 10.9 & 4.8 & 2.2 & 5.1 & 5.6 \\
\hline Other & 0.0 & 0.0 & 0.0 & 0.0 & 0.0 & 0.0 & 0.0 & 0.0 & 0.0 & 0.0 \\
\hline $\begin{array}{l}\text { Not } \\
\quad \text { documented }\end{array}$ & 0.8 & 1.1 & 2.0 & 4.6 & 1.6 & 5.5 & 0.5 & 0.4 & 0.9 & 1.1 \\
\hline \multicolumn{11}{|c|}{ Number of additional VTE risk factors**, \% } \\
\hline $\begin{array}{l}\text { No risk } \\
\text { factors }\end{array}$ & 12.2 & 24.0 & 51.2 & 65.1 & 34.5 & 0.3 & 44.2 & 0.0 & 37.5 & 28.6 \\
\hline $\begin{array}{l}1 \text { or more } \\
\text { risk factors }\end{array}$ & 87.8 & 76.0 & 48.8 & 34.9 & 65.5 & 99.7 & 55.8 & 100.0 & 62.5 & 71.4 \\
\hline 1 risk factor & 34.4 & 41.5 & 36.6 & 25.3 & 39.2 & 71.6 & 41.4 & 1.0 & 40.6 & 38.2 \\
\hline $\begin{array}{l}2+\text { risk } \\
\text { factors }\end{array}$ & 53.4 & 34.5 & 12.2 & 9.6 & 26.3 & 28.1 & 14.4 & 99.0 & 21.9 & 33.2 \\
\hline
\end{tabular}

Classifications and risk factors are adapted from the 7th ACCP Guidelines [1]

${ }^{\dagger}$ General medical includes heart failure, severe respiratory disease, acute myocardial infarction, stroke, and severe infectious disease

${ }^{\ddagger}$ Cardiology: cardiology, cardiovascular disease, or cardiology/electrophysiology; internal medicine and primary care: family practice, family nurse practitioner, general practice, hospitalist, or internal medicine; oncology: oncology or radiation oncology; surgery: cardiothoracic surgery, general surgery, neurosurgery, plastic and reconstructive surgery, or unspecified surgical specialty; orthopedic: orthopedic or orthopedic surgery; other: adult nurse practitioner, anesthesiology, critical care, dentist, dermatology, emergency medicine, family nurse practitioner, gastroenterology, hematology, nephrology, ophthalmology, pathology, physical medicine/ rehabilitation, physician assistant, podiatry, pulmonary, rheumatology, urology, pediatric medicine, radiology, or ear/nose/throat; not documented: could not be determined from the data due to missing values

$\S$ Public payers include medicare, medicaid, veteran's health, and Indian health service

** Defined as any additional risk factors beyond the actual diagnostic groups. Risk factors were determined using primary and secondary diagnosis and procedure codes. In addition to the risk factors defined by each of the seven diagnostic groups, $71.4 \%$ of at-risk patients had at least one additional risk factor for VTE and $33.2 \%$ had two or more risk factors. The top three risk factors for all patients were heart/respiratory failure (34.7\%), acute medical illness (25.7\%) and surgery $(17.3 \%)$

at-risk patients). Additionally, patients frequently received thromboprophylaxis regimens that were of the inappropriate type (25.4\% of at-risk patients); appropriate type but inadequate dose and insufficient duration (13.9\%); appropriate type and sufficient duration but inadequate dose (8.3\%); and appropriate type and adequate dose but insufficient duration (2.7\%). Of patients who received any thromboprophylaxis, $25.3 \%$ received it on only 1 day, $16.1 \%$ on 2 days and $15.2 \%$ on 3 days; it was most often initiated on the first day of the stay $(67.4 \%)$.

Over the 2-year study period, the overall (critical care, surgery and medical conditions combined) quarterly rates of appropriate thromboprophylaxis reflected modest improvement, from $11.6 \%$ in the first quarter of 2005 to $14.5 \%$ in the last quarter of 2006 . However the rate of improvement over time varied across the individual cohorts (Fig. 2). The rate of appropriate thromboprophylaxis varied according to hospital characteristics. Higher rates of appropriate thromboprophylaxis were observed for large hospitals compared to small hospitals (Table 3). Patients were also more likely to receive thromboprophylaxis based on ACCP7 in urban, teaching, and for-profit hospitals.

\section{Discussion}

This study demonstrates that the 7th ACCP guidelines for type, dose and duration of thromboprophylaxis were not implemented to a high degree in participating hospitals. While nearly two-thirds of patients at risk of VTE received some form of thromboprophylaxis, fewer than one in seven (or about one in five of those who received any thromboprophylaxis) received the appropriate type, dose and duration. The proportions of patients receiving appropriate 
Fig. 1 Construction of study sample

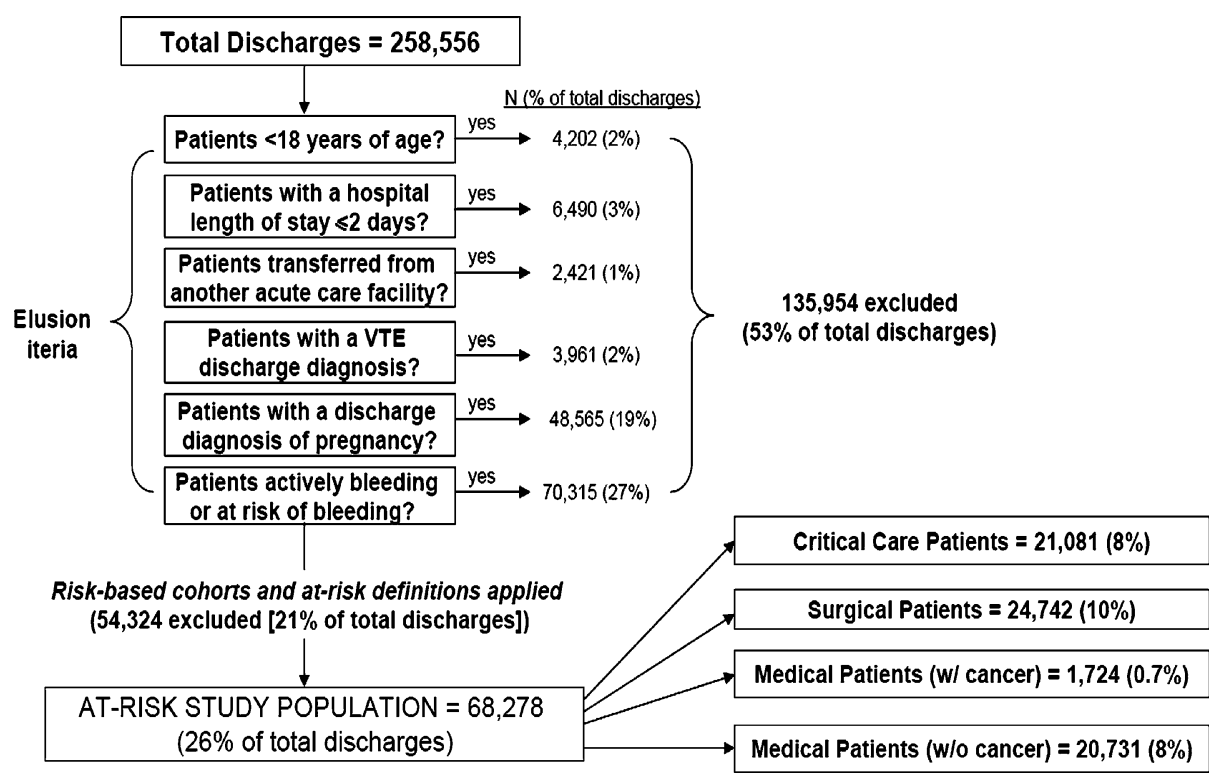

thromboprophylaxis were alarmingly low for every diagnostic group, physician specialty, hospital category, and time period studied.

Hospitals may have intended to implement ACCP7 to varying degrees, and this may partially explain the low levels of appropriate thromboprophylaxis observed in our study. However, the use of alternative guidelines or standards for thromboprophylaxis is unlikely to explain the absence of any thromboprophylaxis in $37 \%$ of at-risk patients. Indeed, the high rate of omission of any form of thromboprophylaxis in medical and surgical patients found in this study is consistent with the findings of other studies $[5,11,12,16]$. In those patients who did get thromboprophylaxis, the regimen did not reflect ACCP7 guidelines nearly $80 \%$ of the time, and the leading cause was inappropriate type (e.g., giving mechanical only when pharmacologic was indicated). Thus, our findings demonstrate a persistent and worrisome gap in the performance of evidence-based thromboprophylaxis for hospitalized patients at participating institutions.

VTE START is, to our knowledge, the only study that has assessed the appropriateness of thromboprophylaxis in multiple US hospitals using the 7th ACCP guidelines for type, dose, and duration. Previous retrospective studies using patient chart reviews have shown that 25 to $84 \%$ of hospitalized patients are at risk of VTE and that only 23 to $46 \%$ of these patients receive any form of thromboprophylaxis [4-8]. However, these studies were based on relatively small samples of patients (range: 100-4124) with medical conditions and relied on the 6th ACCP or non-ACCP guidelines. Two recent, large international registries, using chart review, assessed the use of thromboprophylaxis against ACCP7 [9, 10]. However, the ENDORSE study of 68,183 patients in 32 countries [9] did not include duration of thromboprophylaxis, and the IMPROVE study of 15,156 patients in 12 countries [10] did not assess the appropriateness of the type of the thromboprophylaxis received. Two other recent studies $[11,12]$ used electronic databases of patient records to assess the appropriateness of thromboprophylaxis against the 6th rather than the 7th ACCP guidelines. Yu and colleagues [11] reported appropriate thromboprophylaxis in only $13.3 \%$ of patients across a similar range of diagnostic groups. Amin and colleagues [12] found the rate of appropriate thromboprophylaxis to be $33.9 \%$ among highrisk medical patients. It is worth noting that there is no significant difference between the 6th and the 7th ACCP guidelines in terms of the criteria for appropriate prophylaxis, therefore the bases of the results from our study should be comparable to the bases of the results obtained from those published studies.

Our results should be interpreted in light of several limitations. First, we employed discharge-summary and billing data to assess risk status and appropriateness of thromboprophylaxis. While such electronic data allow for rapid and efficient analysis of all patients in an institution, there is the possibility of measurement error because certain risk factors cannot be fully assessed based on discharge and billing records. This may have led to inaccurate assumptions about a patient's at-risk status or appropriate thromboprophylaxis regimen. For example, we determined that $26 \%$ of all hospitalized patients were at risk of VTE and had no apparent contraindications for thromboprophylaxis. These results are similar to other studies using 


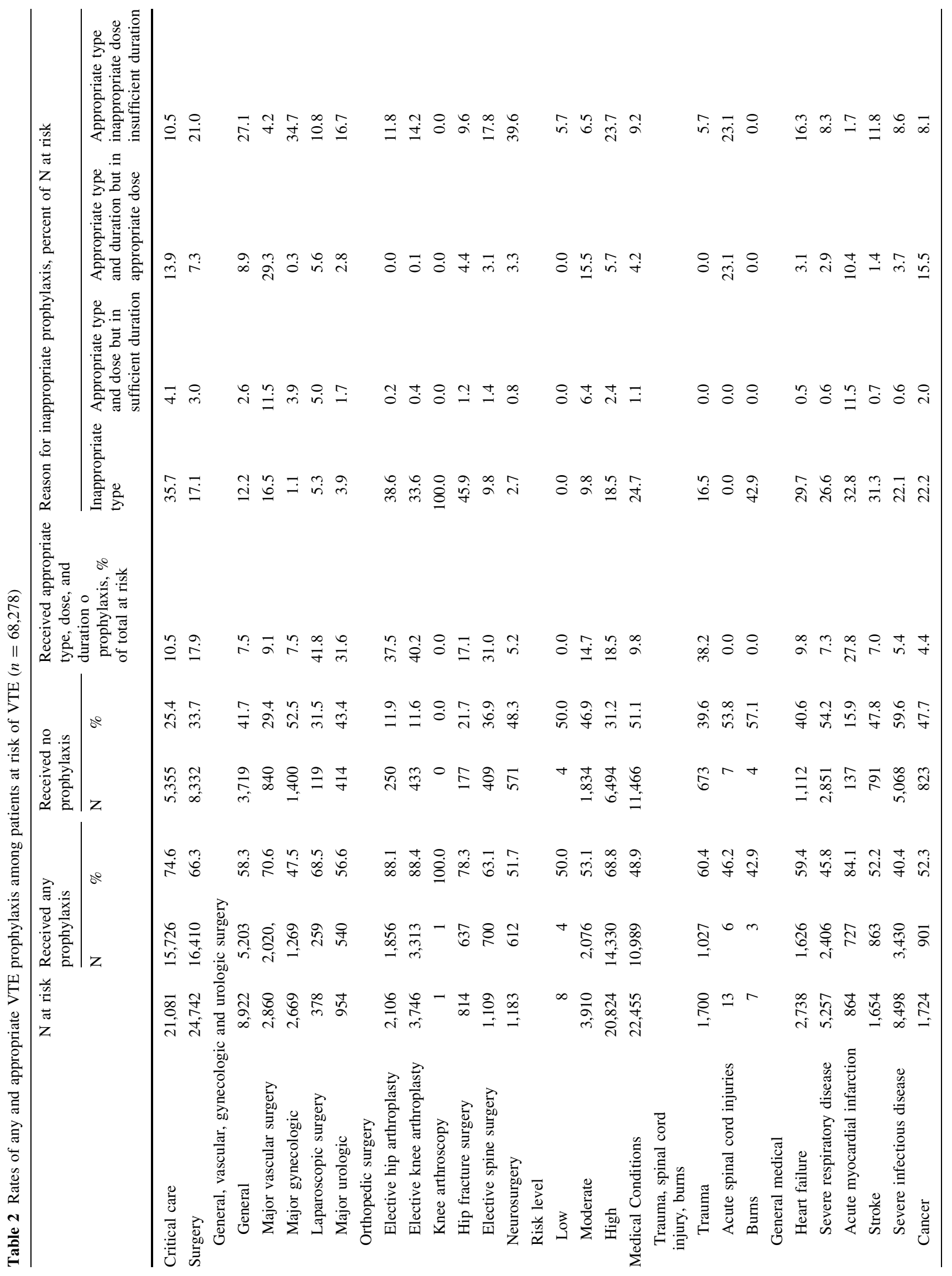




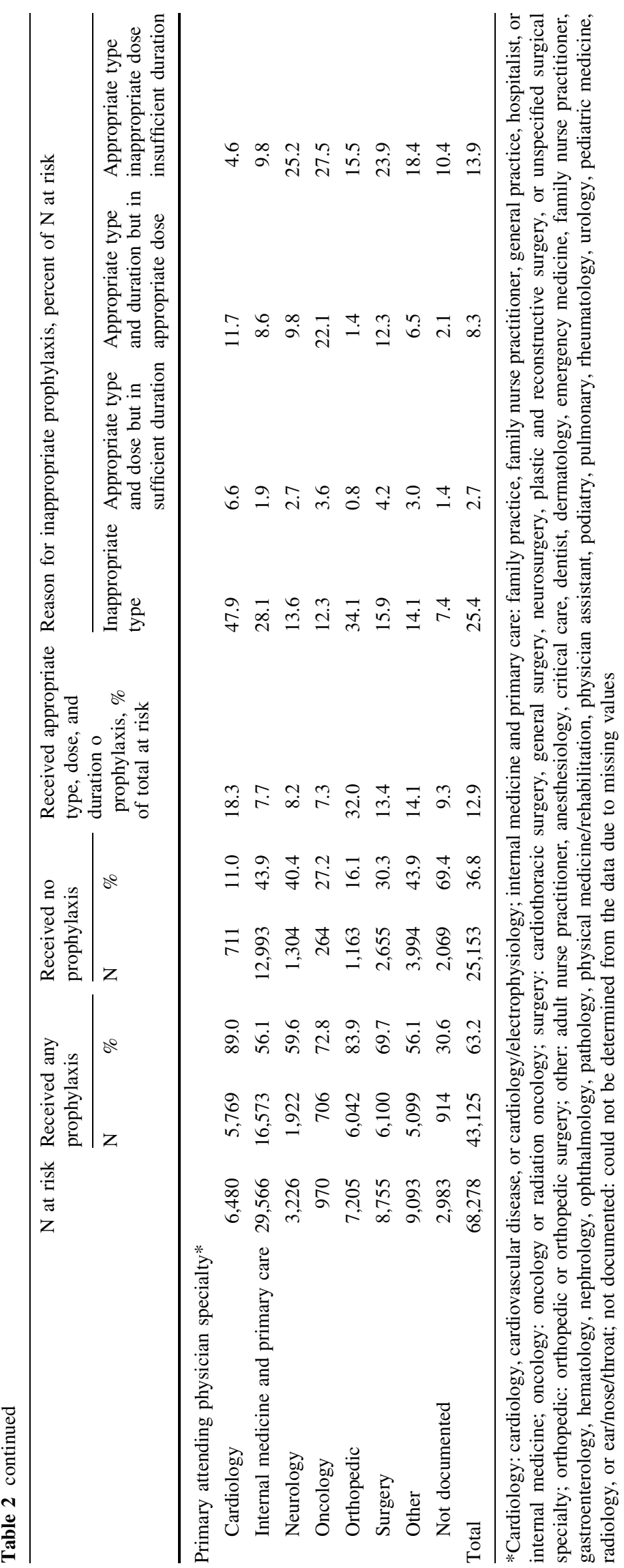


Fig. 2 Patients at risk of VTE who received appropriate prophylaxis by diagnostic group over time $(n=68,278)$

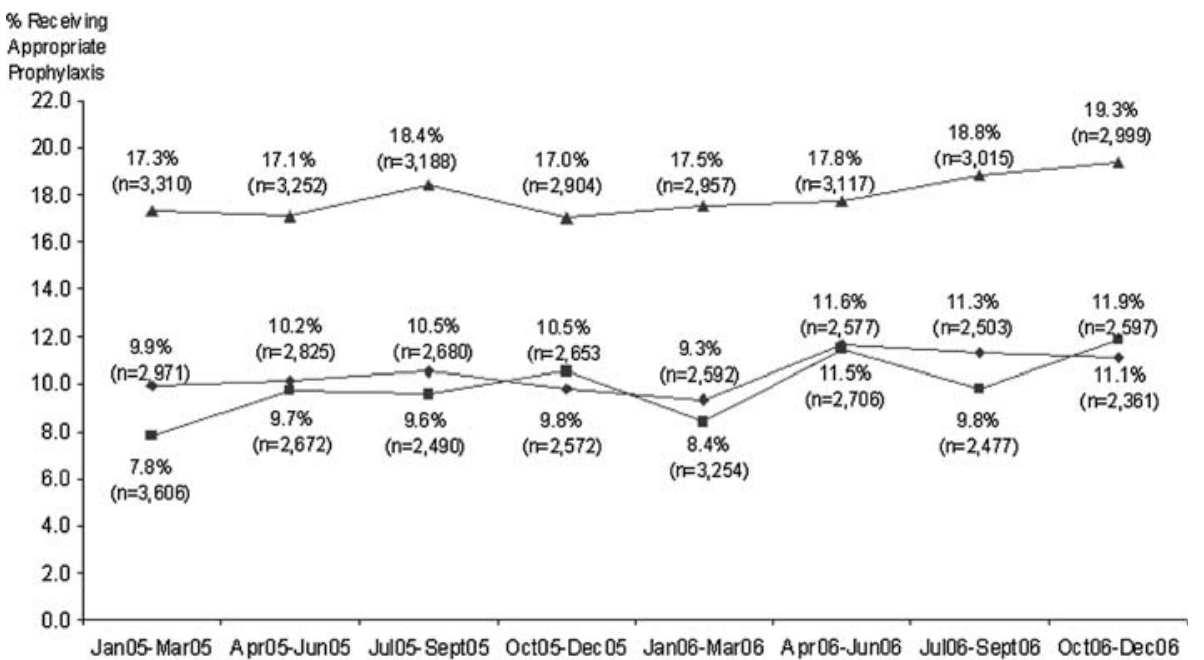

$\rightarrow$ Critical Care $₫$ Surgery $\rightarrow-$ Medical Conditions

Table 3 Rates of any and appropriate VTE prophylaxis among patients at risk of VTE, by hospital characteristics $(n=68,278)$

\begin{tabular}{|c|c|c|c|c|c|c|c|c|c|c|}
\hline \multirow[t]{2}{*}{$\begin{array}{l}\text { Hospital } \\
\text { characteristic }\end{array}$} & \multirow[t]{2}{*}{$\begin{array}{l}\text { Total at } \\
\text { risk, } \mathrm{N}\end{array}$} & \multicolumn{2}{|c|}{$\begin{array}{l}\text { Received } \\
\text { any } \\
\text { prophylaxis }\end{array}$} & \multicolumn{2}{|c|}{$\begin{array}{l}\text { Received no } \\
\text { prophylaxis }\end{array}$} & \multirow{2}{*}{$\begin{array}{l}\text { Received } \\
\text { appropriate } \\
\text { type, dose, } \\
\text { and duration } \\
\text { of prophylaxis } \\
\% \text { of } \mathrm{N} \text { at risk }\end{array}$} & \multicolumn{4}{|c|}{ Reason for inappropriate prophylaxis, percent of $\mathrm{N}$ at risk } \\
\hline & & $\mathrm{N}$ & $\%$ & $\mathrm{~N}$ & $\%$ & & $\begin{array}{l}\text { Inappropriate } \\
\text { type }\end{array}$ & $\begin{array}{l}\text { Appropriate } \\
\text { type and dose } \\
\text { but insufficient } \\
\text { duration }\end{array}$ & $\begin{array}{l}\text { Appropriate } \\
\text { type and } \\
\text { duration but } \\
\text { inappropriate } \\
\text { dose }\end{array}$ & $\begin{array}{l}\text { Appropriate } \\
\text { type but } \\
\text { insufficient } \\
\text { duration }\end{array}$ \\
\hline \multicolumn{11}{|l|}{ Number of beds } \\
\hline $0-100$ & 5,567 & 2,825 & 50.7 & 2,742 & 49.3 & 11.9 & 24.9 & 1.0 & 4.9 & 8.0 \\
\hline $101-500$ & 36,957 & 21,242 & 57.5 & 15,715 & 42.5 & 11.3 & 22.1 & 2.9 & 6.7 & 14.5 \\
\hline $501-1000$ & 25,754 & 19,058 & 74.0 & 6,696 & 26.0 & 15.4 & 30.2 & 2.8 & 11.4 & 14.2 \\
\hline $1000+$ & - & - & 0.0 & & 0.0 & 0.0 & 0.0 & 0.0 & 0.0 & 0.0 \\
\hline \multicolumn{11}{|c|}{ Geographic location } \\
\hline Urban & 59,740 & 39,523 & 66.2 & 20,217 & 33.8 & 13.6 & 26.0 & 3.0 & 9.2 & 14.3 \\
\hline Rural & 8,538 & 3,602 & 42.2 & 4,936 & 57.8 & 8.4 & 20.7 & 0.5 & 1.9 & 10.6 \\
\hline \multicolumn{11}{|l|}{ Teaching status } \\
\hline Teaching & 10,791 & 6,191 & 57.4 & 4,600 & 42.6 & 15.6 & 19.1 & 2.1 & 3.0 & 17.6 \\
\hline $\begin{array}{c}\text { Non- } \\
\text { Teaching }\end{array}$ & 57,487 & 36,934 & 64.2 & 20,553 & 35.8 & 12.4 & 26.5 & 2.8 & 9.3 & 13.2 \\
\hline \multicolumn{11}{|l|}{ Type } \\
\hline $\begin{array}{l}\text { Not-for- } \\
\text { profit }\end{array}$ & 57,487 & 36,934 & 64.2 & 20,553 & 35.8 & 12.4 & 26.5 & 2.8 & 9.3 & 13.2 \\
\hline For-profit & 10,791 & 6,191 & 57.4 & 4,600 & 42.6 & 15.6 & 19.1 & 2.1 & 3.0 & 17.6 \\
\hline \multicolumn{11}{|l|}{ Payer mix } \\
\hline Public & 33,601 & 20,507 & 61.0 & 13,094 & 39.0 & 10.3 & 27.7 & 1.8 & 7.7 & 13.5 \\
\hline Commercial & 30,088 & 19,826 & 65.9 & 10,262 & 34.1 & 15.5 & 23.1 & 3.7 & 8.8 & 14.8 \\
\hline Other & 4,589 & 2,792 & 60.8 & 1,797 & 39.2 & 15.6 & 22.8 & 2.8 & 9.3 & 10.4 \\
\hline
\end{tabular}

hospital discharge-summary and billing data (13-31\%)[11, $15]$ but at the lower end of the range of results from chartbased evaluations $(25-84 \%)[4-8,16]$. This may be due to our large sample representing more categories of patients than previous studies, but it may also reflect our liberal exclusion criteria for potential bleeding risk, which 
increased the number of patients for whom thromboprophylaxis was contraindicated and reduced the proportion at risk of VTE. Our approach is consistent with previous studies using discharge-summary and billing data[11, 12], and reflects a desire to under-estimate rather than overestimate the proportion of patients at risk of VTE. With this in mind, it is worth noting that we had no access to patients' clinical history such as recent ( $<30$ days) GI bleeding, therefore we might have been overestimated the at risk population as described herein. Similarly, we may have overestimated the number of patients receiving appropriate thromboprophylaxis because we imposed no upper bound on dose and a low threshold for appropriate duration. Both of these criteria reflect our intent to be as liberal as possible where there was uncertainty in our ability to determine appropriate thromboprophylaxis. Finally, our small sample of 16 hospitals was not intended to be nationally representative, and the fact that 13 of them were part of a single hospital system may have reduced the variance within the sample. Further, the observed variation in the rate of prophylaxis across the participating hospitals are likely to be confounded due the fact that some of these hospitals had some initiative in place for improving prophylaxis. The extent to which the low levels of thromboprophylaxis found in these hospitals reflect the levels in other US hospitals is unknown.

Our results demonstrate an alarmingly low degree of implementation of the 7th ACCP guidelines and imply the need for urgent action by physicians and health systems to assess risk and deliver appropriate thromboprophylaxis. Interventions in the form of educational programs, risk stratification, critical pathways and alert tools have been effective in increasing the rate of thromboprophylaxis [8, 11, 17-19]. An additional strength of this project was the delivery of benchmarking reports to participating hospitals, for use in the development and evaluation of their own quality improvement initiatives. Institutions may find that analyzing their administrative databases on all patients is a more efficient and comprehensive method than manual chart abstraction of small samples of patients for assessing thromboprophylaxis rates and the impact of quality improvement initiatives.

\section{Conclusions}

This study demonstrates the significant gap between evidence-based thromboprophylaxis recommendations and actual clinical practice in a large sample of hospitalized patients. More than $25 \%$ of hospitalized patients were at risk of VTE, but fewer than one in seven of these patients received thromboprophylaxis that met criteria for recommended type, dose and duration. We recommend intensive efforts to improve the degree of implementation of current guidelines for appropriate thromboprophylaxis.

Acknowledgment This project was funded by sanofi-aventis. The VTE START Steering Committee included Drs. Amin, Spyropoulos, Dobesh, Shorr, Benner, and Jonothan Tierce of IMS Health. The authors are grateful to David Klingman, Jay Lin, Alan Mann, Cindy Eisenschenk, and Sarah Peirce for their contributions to the analysis, site support, and manuscript.

Open Access This article is distributed under the terms of the Creative Commons Attribution Noncommercial License which permits any noncommercial use, distribution, and reproduction in any medium, provided the original author(s) and source are credited.

\section{Appendix}

See Tables 4, 5

Table 4 Criteria for determining appropriate prophylaxis by study cohort

\begin{tabular}{lll}
\hline Study cohort & Additional stratification & Appropriate prophylaxis \\
\hline Critical care & & \\
Critical care & - All patients & Type: LDUH or LMWH \\
& $\bullet$ Major trauma or orthopedic surgery & Dose: See minimum prophylaxis dose in Table 5, technical \\
& appendix. \\
& Duration: LOS-1 (medical) LOS-2 (surgical) \\
& Type: LMWH \\
& Dose: See minimum prophylaxis dosein Table 5, technical \\
& appendix. \\
& Duration: LOS -1 (trauma) LOS-2 (orthopedic surgery) \\
\hline
\end{tabular}


Table 4 continued

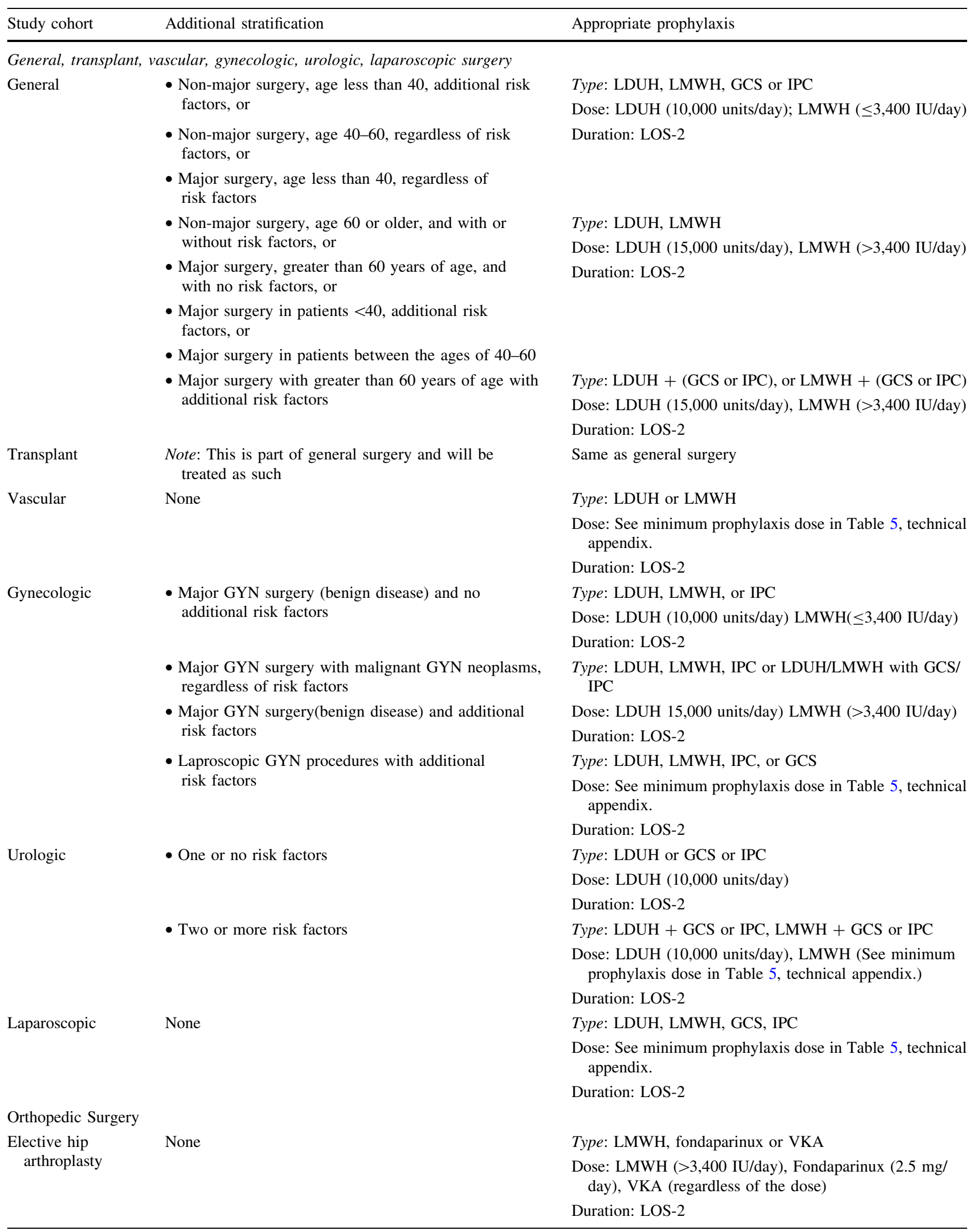


Table 4 continued

\begin{tabular}{|c|c|c|}
\hline Study cohort & Additional stratification & Appropriate prophylaxis \\
\hline $\begin{array}{l}\text { Elective knee } \\
\text { arthroplasty }\end{array}$ & None & $\begin{array}{l}\text { Type: LMWH, Fondaparinux or VKA } \\
\text { Dose: LMWH ( }>3,400 \mathrm{IU} / \text { day), Fondaparinux }(2.5 \mathrm{mg} / \\
\text { day), VKA (regardless of the dose) } \\
\text { Duration: LOS-2 }\end{array}$ \\
\hline Knee arthroscopy & None & $\begin{array}{l}\text { Type: LMWH } \\
\text { Dose: See minimum prophylaxis dose in Table 5, technical } \\
\quad \text { appendix. } \\
\text { Duration: LOS-2 }\end{array}$ \\
\hline Hip fracture surgery & & $\begin{array}{l}\text { Type: LMWH, fondaparinux, VKA, LDUH } \\
\text { Dose: LMWH(>3,400/day) Fodaparinux ( } 2.5 \mathrm{mg} / \text { day }) \\
\text { VKA (regardless of dose) LDUH ( } 10,000 \text { units/day) } \\
\text { Duration: LOS-2 }\end{array}$ \\
\hline Elective spine surgery & - Two or more risk factors & $\begin{array}{l}\text { Type: LDUH, LMWH, IPC, or GCS } \\
\text { Dose: See minimum prophylaxis dose in Table 5, technical } \\
\text { appendix. } \\
\text { Duration: LOS-2 } \\
\text { Type: LDUH + (any GCS or IPC), LMWH + (any GCS or } \\
\text { IPC) } \\
\text { Dose: See minimum prophylaxis dose in Table 5, technical } \\
\text { appendix. } \\
\text { Duration: LOS-2 }\end{array}$ \\
\hline
\end{tabular}

Neurosurgery

Neurosurgery

- Age 40 or above regardless of risk factors

Trauma, spinal cord injuries, burns

Trauma None

Spinal cord injuries None

Burns None

Acutely Ill medical patients

Heart failure None

\section{Type: LMWH, UFH, IPC or GCS}

Dose: See minimum prophylaxis dose in Table 5, technical appendix.

Duration: LOS-2

Type: $\mathrm{LMWH}+$ (IPC or GCS), or UFH + (IPC or GCS)

Dose: See minimum prophylaxis dose in Table 5, technical appendix.

Duration: LOS-2

Type: LMWH, GCS or IPC

Dose: See minimum prophylaxis dose in Table 5, technical appendix.

Duration: LOS-1

Type: LMWH, LMWH + IPC, or LDUH + IPC

Dose: See minimum prophylaxis dose in Table 5, technical appendix.

Duration: LOS-1

Type: LDUH or LMWH

Dose: See minimum prophylaxis dose in Table 5, technical appendix.

Duration: LOS-1

Type: LDUH or LMWH

Dose: See minimum prophylaxis dose in Table 5, technical appendix.

Duration: LOS-1 
Table 4 continued

\begin{tabular}{|c|c|c|}
\hline Study cohort & Additional stratification & Appropriate prophylaxis \\
\hline $\begin{array}{l}\text { Severe respiratory } \\
\text { infection }\end{array}$ & None & $\begin{array}{l}\text { Type: LDUH or LMWH } \\
\text { Dose: See minimum prophylaxis dose in Table } 5 \text {, technical } \\
\text { appendix. } \\
\text { Duration: LOS- } 1\end{array}$ \\
\hline $\begin{array}{l}\text { Acute myocardial } \\
\text { infraction }\end{array}$ & None & $\begin{array}{l}\text { Type: LDUH or LMWH } \\
\text { Dose: See minimum prophylaxis dose in Table } 5 \text {, technical } \\
\text { appendix. } \\
\text { Duration: LOS-1 }\end{array}$ \\
\hline Stroke & None & $\begin{array}{l}\text { Type: LDUH or LMWH } \\
\text { Dose: See minimum prophylaxis dose in Table } 5 \text {, technical } \\
\text { appendix. } \\
\text { Duration: LOS-1 }\end{array}$ \\
\hline $\begin{array}{l}\text { Severe infectious } \\
\text { disease }\end{array}$ & None & $\begin{array}{l}\text { Type: LDUH or LMWH } \\
\text { Dose: See minimum prophylaxis dose in Table } 5 \text {, technical } \\
\text { appendix. } \\
\text { Duration: LOS- } 1\end{array}$ \\
\hline \multicolumn{3}{|l|}{ Cancer } \\
\hline $\begin{array}{l}\text { Without surgery } \\
\text { (medical } \\
\text { conditions) }\end{array}$ & & Assessed according to the accompanying medical condition \\
\hline
\end{tabular}

Table 5 Label based dosing for pharmacologic prophylaxis and the minimum dose per day utilized in the study

\begin{tabular}{|c|c|c|}
\hline Drugs & Label prophylaxis dosing regimen & Minimum (per day) \\
\hline \multicolumn{3}{|l|}{ Fondaparinux } \\
\hline $\begin{array}{l}\text { Fondaparinux }\left(\text { Arixtra }^{\circledR}\right) \text {-THR, TKR, HFS, } \\
\text { abdominal surgery }\end{array}$ & $2.5 \mathrm{mg}$ SQ QD & $2.5 \mathrm{mg}$ \\
\hline \multicolumn{3}{|l|}{$U F H$} \\
\hline Heparin & $\begin{array}{l}5,000 \text { USP units SQ } 2-3 \text { times per day; 7,500 } \\
\text { USP units SQ } 2 \text { times per day }\end{array}$ & $10,000 \mathrm{IU}$ SQ \\
\hline \multicolumn{3}{|l|}{$L M W H$} \\
\hline Tinzaparin $\left(\right.$ Innohep $\left.{ }^{\circledR}\right)$ & 75 units $/ \mathrm{kg}$ & $4,500 \mathrm{IU}^{*}$ \\
\hline $\begin{array}{l}\text { Dalteparin }\left(\text { Fragmin }^{\circledR}\right) \text { - THR, abdominal surgery, } \\
\text { medically ill }\end{array}$ & 2,500-5,000 anti-Xa IU SQ QD & 2,500 IU \\
\hline $\begin{array}{l}\left.\text { Enoxaparin (Lovenox }{ }^{\circledR}\right) \text { - THR, TKR, abdominal surgery, } \\
\text { medically ill }\end{array}$ & $\begin{array}{l}30 \mathrm{mg} \text { SQ BID or } 40 \mathrm{mg} \text { QD (obese patient }=40 \mathrm{mg} \\
\text { BID; renal dosing }=30 \mathrm{mg} \text { QD) }\end{array}$ & $30 \mathrm{mg}(3,000 \mathrm{IU})$ \\
\hline \multicolumn{3}{|l|}{ VKA } \\
\hline Warfarin & $2-10 \mathrm{mg}$ PO QD adjusted to INR $=2-3$ & $2 \mathrm{mg}$ \\
\hline
\end{tabular}

*Assuming an average body weight of $60 \mathrm{KG}$

BID: twice daily; HFS hip fracture surgery; INR international normalized ratio; $I U$ international units; $S Q$ subcutaneous; $Q D$ once daily; $T H R$ total hip replacement; TKR total knee replacement

Sources: Package labeling; Nutescu EA, Wittkowsky AK, Dobesh PP, Hawkins DW, Dager WE. Choosing the appropriate antithrombotic agent for the prevention and treatment of VTE: a case-based approach. Ann Pharmacother 2006 Sep;40(9):1558-71. Epub 2006 Aug 15

\section{References}

1. Geerts WH, Pineo GF, Heit JA et al (2004) Prevention of venous thromboembolism: the seventh ACCP conference on antithrombotic and thrombolytic therapy. Chest 126:338S-400S

2. Joint Commission on Accreditation of Healthcare Organizations. National consensus standards for prevention and care of venous thromboembolism (VTE) (2007) http://www.jointcommission.org/ PerformanceMeasurement/PerformanceMeasurement/VTE.htm. Accessed 6 Dec

3. Centers for Medicare and Medicaid Services, US Department of Health and Human Services (2008) Medicare program; hospital outpatient prospective payment system and CY 2007 payment rates; CY 2007 update to the ambulatory surgical center covered 
procedures list; Medicare administrative contractors; and reporting hospital quality data for FY 2008 inpatient prospective payment system annual payment update program-HCAHPS survey, SCIP, and mortality. Final rule with comment period and final rule. Fed Regist 2006 Nov 24; 71(226):67959-68401. http://www.cms.hhs.gov/quarterlyproviderupdates/downloads/ cms1506fc.pdf. Accessed 18 Feb

4. Ageno W, Squizzato A, Ambrosini F et al (2002) Thrombosis prophylaxis in medical patients: a retrospective review of clinical practice patterns. Haematologica 87:746-750

5. Kahn SR, Panju A, Geerts W et al (2007) Multicenter evaluation of the use of venous thromboembolism prophylaxis in acutely ill medical patients in Canada. Thromb Res 119:145-155

6. Rahim SA, Panju A, Pai M et al (2003) Venous thromboembolism prophylaxis in medical inpatients: a retrospective chart review. Thromb Res 111:215-219

7. Stark JE, Kilzer WJ (2004) Venous thromboembolic prophylaxis in hospitalized medical patients. Ann Pharmacother 38:36-40

8. Stinnett JM, Pendleton R, Skordos L et al (2005) Venous thromboembolism prophylaxis in medically ill patients and the development of strategies to improve prophylaxis rates. Am J Hematol 78:167-172

9. Cohen AT, Tapson VF, Bergmann JF et al (2008) ENDORSE investigators. Venous thromboembolism risk and prophylaxis in the acute hospital care setting (ENDORSE study): a multinational cross-sectional study. Lancet 371:387-394

10. Tapson VF, Decousus H, Chong BH et al (2007) IMPROVE investigators. Venous thromboembolism prophylaxis in acutely ill hospitalized medical patients: findings from the International Medical Prevention Registry on Venous Thromboembolism. Chest 132:936-956

11. Yu H, Dylan ML, Lin J et al (2007) Hospitals' compliance with prophylaxis guidelines for venous thromboembolism. Am J Health Syst Pharm 64:69-76
12. Amin A, Stemkowski S, Lin J et al (2007) Thromboprophylaxis rates in US medical centers: success of failure? J Thromb Haemost 5:1610-1616

13. United State Department of Health and Human Services (2007) Office for civil rights. Summary of the HIPAA privacy rule. http://www.hhs.gov/ocr/privacysummary.pdf. Accessed 6 Dec

14. Cardiovascular Disease Educational and Research Trust; Cyprus Cardiovascular Disease Educational and Research Trust; European Venous Forum; International Surgical Thrombosis Forum; International Union of Angiology; Union Internationale de Phlébologie (2006) Prevention and treatment of venous thromboembolism: international consensus statement (guidelines according to scientific evidence). Int Angiol 25:101-161

15. Anderson FA, Zayaruzny M, Heit JA et al (2007) Estimated annual numbers of US acute-care hospital patients at risk for venous thromboembolism. Am J Hematol 82:777-782

16. Piazza G, Seddighzadeh A, Goldhaber SZ (2007) Double trouble for 2, 609 hospitalized medical patients who developed deep vein thrombosis: prophylaxis omitted more often and pulmonary embolism more frequent. Chest 132:554-561

17. Vallano A, Arnau JM, Miralda GP et al (2004) Use of venous thromboprophylaxis, adherence to guideline recommendations: a cross-sectional study. Thromb J 2:3

18. Dobesh PP, Stacy ZA (2005) Effect of a clinical pharmacy education program on improvement in the quantity and quality of venous thromboembolism prophylaxis for medically ill patients. J Manag Care Pharm 11:755-762

19. Kucher N, Koo S, Quiroz R et al (2005) Electronic alerts to prevent venous thromboembolism among hospitalized patients. N Engl J Med 352:969-977 